\title{
Synthesis of Aminoindanes via a Novel C-H Activation-[3+2]-Annulation Strategy
}

\section{Category}

Metal-Catalyzed

Asymmetric

Synthesis and

Stereoselective

Reactions

\section{Key words}

iridium

[3+2] annulation

C-H activation
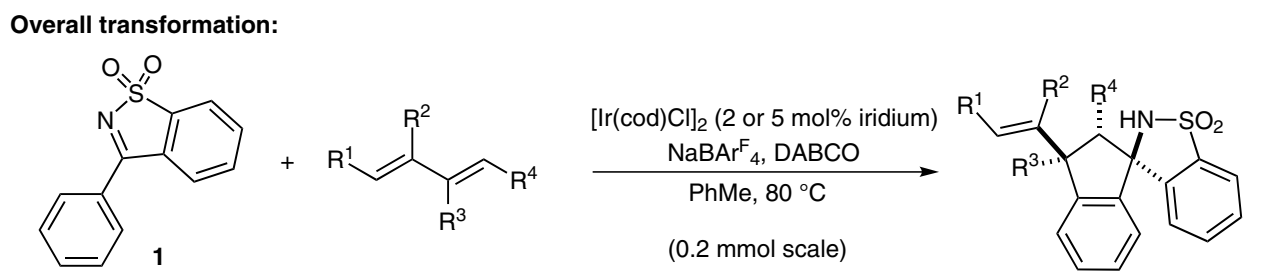

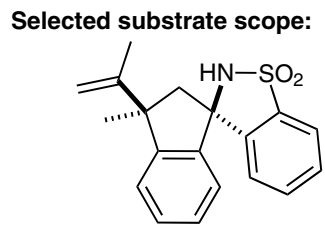

$96 \%$ yield

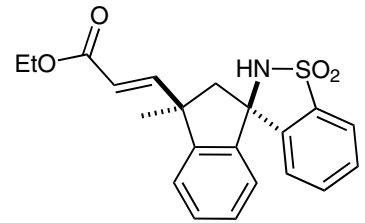

$99 \%$ yield

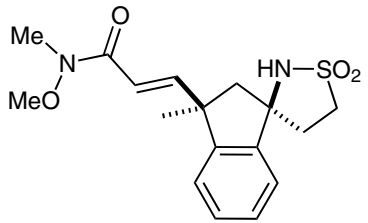

$79 \%$ yield

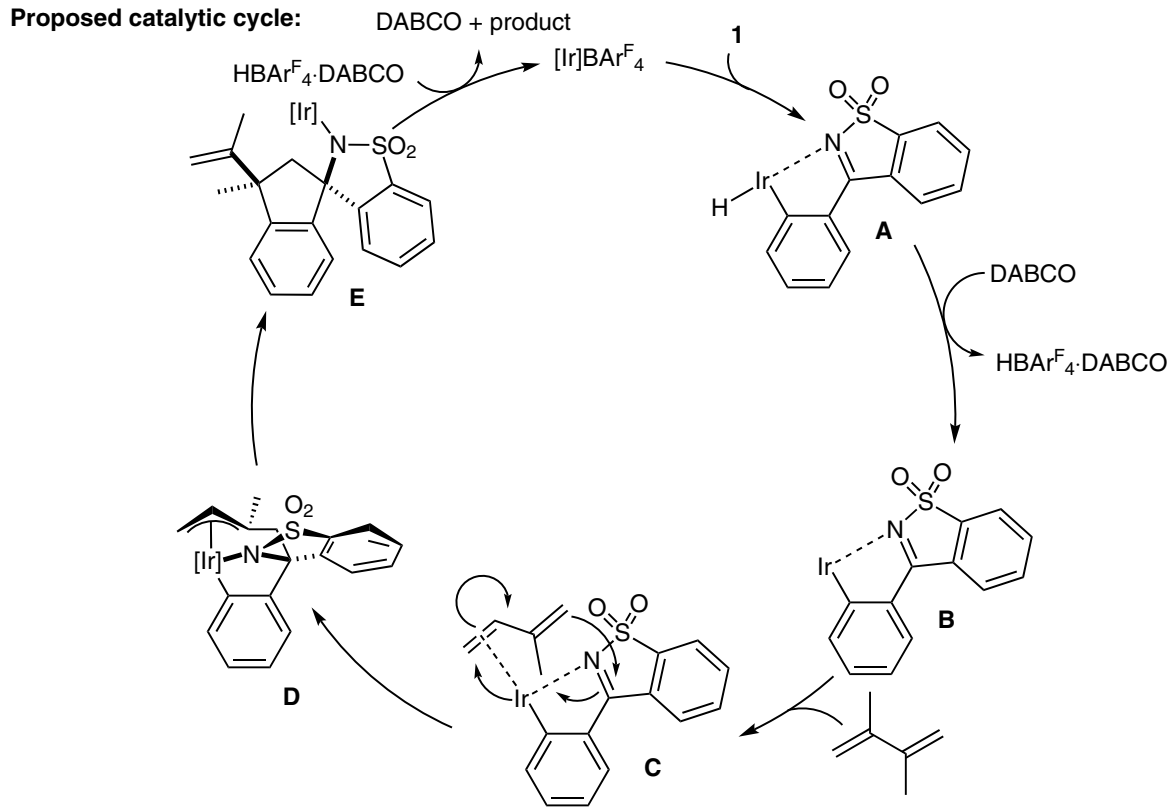

Significance: Directed ortho $\mathrm{C}-\mathrm{H}$ functionalization has become a hot topic in organic synthesis in recent years. A novel extension is reported by Nishimura and co-workers, who accomplished an iridium-catalyzed annulation of $\mathrm{N}$-sulfonyl ketimines with 1,3-dienes to provide complex aminoindane derivatives.
Comment: This transformation tolerates a wide variety of 1,3-diene substrates, and products are afforded in good to excellent yields and high regioand stereoselectivity. Key to the proposed mechanism is the intramolecular aryl-iridium- $\pi$-allyl intermediate $\mathbf{D}$.

SYNFACTS Contributors: Mark Lautens, David A. Petrone 